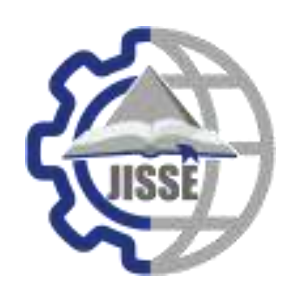

\begin{tabular}{c}
\hline \hline JISSE \\
ISSN: 2636-4425 \\
\hline \hline
\end{tabular}

\title{
Design, Manufacturing and Testing of a Hydraulic Press to Produce Oil from Egyptian Jatropha Seeds
}

\author{
Said M. A. Ibrahim ${ }^{1}$, K.A. Abed ${ }^{2}$, M.S. Gad ${ }^{3}$, H.M. Abu Hashish ${ }^{2, *}$ \\ ${ }^{I}$ Mechanical Engineering Department, Faculty of Engineering, Al-Azhar University, Cairo, Egypt. \\ ${ }^{2}$ Mechanical Engineering Department, Engineering Research Division, National Research Centre, Giza, Egypt. \\ ${ }^{3}$ Mechanical Engineering Department, Faculty of Engineering, Fayoum University, Egypt.
}

\section{A R T I C L E I N F O \\ Article history: \\ Received:26-12-2019 \\ Accepted:30-12-2019 \\ Online:31-12-2019}

Keywords:

Hydraulic Press

Jatropha Seeds

Jatropha oil

Design

Yield

\begin{abstract}
A B S T R A C T
Increase of fossil fuel consumption rates, depletion of conventional fuel, harmful exhaust emissions increase and global warming. This concludes to search for alternative fuels. This study was performed to produce a suitable alternative fuel. The produced oil from non-edible jatropha seeds becomes researcher's interest because of the higher price of edible vegetable oils. Design, manufacturing, and testing of an efficient system to produce the oil from Egyptian jatropha seeds was carried out. This hydraulic press squeezes jatropha seeds to produce the oil. It is designed to obtain the maximum oil yield. Physical and chemical parameters such as specific gravity, kinematic viscosity, calorific value, flash number and cetane number of the extracted oils were measured. Time of oil extracted from jatropha seeds is 720 minutes at a yield of $11 \%$. The extracted Jatropha oil gave light color because of its low FFA of 5\%. The density and viscosity of the extracted oil decreased as the temperature increases. The flash point of the oil is higher than diesel oil. Calorific value of the produced jatropha oil was $39201 \mathrm{~kJ} / \mathrm{kg}$. Jatropha biodiesel oxidation instability increased for hydraulic extraction due to its content of oleic and linoleic acids.
\end{abstract}

\section{1 . Introduction}

The researchers have been directed to find suitable alternative fuels due to fuel crisis and global warming. Jatropha plants are cultivated in sewage bonds and desert. Extraction of jatropha oil can be produced either chemically or by mechanical presses. Biodiesel has become environmentally friendly and more attractive since it is obtained from renewable resources, in addition to its benefits $[1,2]$.

Various types of oil expellers were used for jatropha oil extraction. Sundhara and Komet expellers were utilized. Jatropha oil extraction was done mechanically (by pressing the kernels), chemically, and enzymatically. The mechanical press prototype had cast iron heavy parts and iron sheets. The mechanical press was driven electrically. The oil is extracted from the seeds using traditional manual methods in rural areas. A single screw mechanical expeller was used as Komet expeller. Chemical

* Hassan Abu Hashish, Mechanical Engineering Department, National Research Centre, Giza, Egypt, 00201008899248, HM.AbuHashish@nrc.sci.eg methods were used for oil extraction like aqueous enzymatic treatment. Ultra-sonication had been used as an effective method for jatropha oil yield increase of 74\% [3-6].

Soxhlet is used as a reference conventional extraction method. Other methods are compared to Soxhlet. Most extraction methods were like Soxhlet, but they require a long time and large amount of solvents. Most extraction processes are simple in performance and did not require specialized personnel. These methods are cheap, so they have been favored to be used widely in industries and laboratories [7-9]. Mechanical processes followed by solvent ones can be used in oil extraction from seeds. Soybeans have lower oil content, but sunflower seeds, palm and rapeseed have higher oil contents [10-12].

Pretreatment of jatropha curcas seeds for oil extraction consumes approximately $24 \%$ of the total internal energy in solvent extraction and $66 \%$ in mechanical extraction. Seed pretreatment degrades quality energy before oil extraction. Mechanical extraction is more energetically efficient method. 
Solvent extraction of Jatropha curcas oil is $79 \%$ efficient, but that of mechanical extraction of $96 \%$ [13]. Biodiesel was produced from jatropha oil. Chemical and physical properties such as density, kinematic viscosity, flash point, pour point and cloud point were evaluated for jatropha oil and compared to conventional fossil diesel. Jatropha oil properties allow to be used in conventional diesel engines without any modifications [13,14].

The ram press produced oil in rural areas with small amounts. The strainer press produced oil more effectively and uses manual operation. The cylinder press extracted the oil from Jatropha seeds on a large scale with oil yields of about $89.4 \%$ [15]. Performance of a screw press machine for Jatropha seeds extraction was studied under different machine capacity and seed moisture content. The oil yield, extraction efficiency, specific energy, and operational cost were studied. The highest value of oil yield and extraction efficiency were $43 \mathrm{~kg} / \mathrm{hr}$ and $81 \%$, respectively $[2,16-18]$. Jatropha seeds were the ideal sustainable and low-cost source of oil feedstock for biodiesel production [19].

The behavior of oil expression was very sensitive to seeds preparation. The presence of seed shells built a porous solid. The specific mechanical energy of oil expression was less than $5 \%$ of the energy content of the oil [20]. Oil extraction from jatropha seeds by mechanical pressing was carried out using twin-screw press. The operating conditions such as screw configuration, screw rotation speed and press temperature influenced oil yield. The highest oil yield was 71\% [21].

Hydraulic press was used to investigate the effect of process parameters on oil recovery. Oil extraction was done for compression speed of $0.05-2.5 \mathrm{MPa} / \mathrm{s}$, applied pressure of 5-25 $\mathrm{MPa}$, pressing temperature of $25-105{ }^{\circ} \mathrm{C}$, pressing time of $1-30$ $\mathrm{min}$, and preheating time of $0-30 \mathrm{~min}$. Oil recovery increased with the increase in temperature and pressing time. The optimum oil recovery was obtained when Jatropha seeds were pressed at $15 \mathrm{MPa}$ and temperature of $90{ }^{\circ} \mathrm{C}$ for $10 \mathrm{~min}$ of pressing [22,23].

Jatropha seeds were pressed under height of $80 \mathrm{~mm}$ using the pressing vessel diameter $60 \mathrm{~mm}$. The dependency between compressive force and deformation was described and the mass of emerged oil was measured [24]. The seeds must be previously crushed with a hammer mill to particles smaller than $2 \mathrm{~mm}$ diameter and dry heating treatment at optimization conditions [25].

The literature gives studies on the effect of seed pretreatment on hydraulic pressing of Jatropha oil. This research aimed to study the effect of hydraulic extraction process on fatty acid content, oil yield and oil properties. The target of this work is to design and manufacture a hydraulic press to press Egyptian jatropha seeds with lower cost and local materials. Hydraulic press was designed and tested. The aim of the hydraulic press is to extract jatropha oil from the seeds with higher yield. The selected materials were tested for the applied load. Hydraulic press parts were manufactured for easy maintenance and movement. Produced oil properties of the extracted oil were evaluated to show the effect of the extraction method on physical and chemical properties.

\section{2 . Research Approach and Methodology}

The design of hydraulic press relies on Pascal's principle. The system is a press acting as a pump that has humble mechanical force acting over a small cross-sectional area. The other part is a press having a larger area that generates a large mechanical force correspondingly. If the pump is separated from the press cylinder, only small diameter tubing which resists pressure more easily is needed. The pressure on a restricted fluid is transmitted without being diminished and acts with equal force on equal areas at $90 \mathrm{o}$ to the container wall. When the press is pushed internally, the incompressible oil is displaced, and the volume displaced by the small press is equal to the volume displaced by the large press. This causes a difference in the displacement which is proportional to the ratio of the press head area. Thus, the small press must be moved a large distance to allow the large press to move significantly. In this study, the applied force increased on the larger press area, the applied force over a distance should be decreased.

Jatropha oil extraction using hydraulic pressing was investigated. A sieve plate covered with fine mesh was used. The pressing chamber has a controlled temperature from 30 to $1000 \mathrm{C}$ with a fixed diameter. The press pressure is up to $100 \mathrm{MPa}$. The hydraulic plunger supplied with sensors for temperature, pressure and position measurements. The piston was lowered on the top of the seeds. The seeds were laid in the press chamber then the piston was pressed on the seeds. The pressing temperature can be equilibrated for at least $30 \mathrm{~min}$ on the seeds without mechanical pressure which is raised up to $4 \mathrm{MPa}$ for $10 \mathrm{sec}$ after that. The pressure was extended linearly at the desired speed until it reached to the final pressure. This extraction yield was $10 \%$ of the extracted oil [26].

\subsection{Design and Manufacturing of the Hydraulic Press}

The exerted pressure with a machine is termed a press. The presses operated on the principles of hydrostatic pressure called hydraulic. Screw presses used the transmitting power and mechanical presses to transmit power [27-30]. In the hydraulic press, fluid under pressure produced the generated, transmitted and amplified force. The liquid system provided a medium of power transmission and amplification. A smaller piston area transfers the fluid to a cylinder of larger piston area and thus amplifying the force under high pressure.

The hydraulic press contained a pump produced the motive power for the fluid. The power transmission through the pipes, connectors and control devices were caused by the hydraulic fluid. The motor converts the hydraulic energy into useful work [27-30]. A more positive response with the change in input pressure is the main advantages of hydraulic presses. The applied force can be accurately controlled. The force magnitude was shown during the entire working stroke of the ram travel. The large nominal required force was shown by hydraulic presses[31].

The fluid power in the systems is required [32]. The primary aim in the system design is to transpose the desired system performance into system hydraulic pressure and volume flow rate. It was desired to match the characteristics with the available system input to sustain operation. The maximum load is a 
principal parameter in the design $(150 \mathrm{kN})$. Other vital factors are the distance that the load resistance has to move (piston stroke $=$ $600 \mathrm{~mm}$ ), the system pressure, the cylinder area (piston diameter $=80 \mathrm{~mm}$ ), and the volume flow rate of the working fluid. The hydraulic cylinder, the frame, and the hydraulic circuit are the critical components in the design as given in Figure 1.

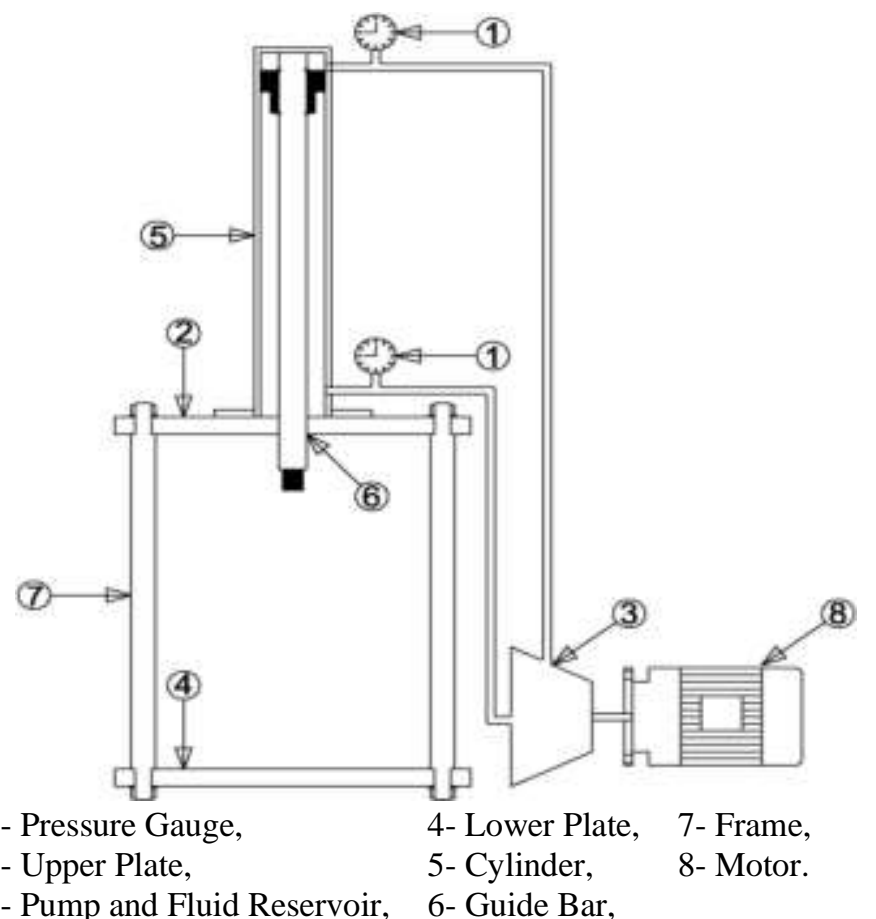

Figure 1: A Schematic diagram of the hydraulic press.

The hydraulic cylinder is tubular in structure and the piston slides inside it. The design included the cylinder minimum wall thickness, the end cover plate, the flange thickness, the specifications and size of bolts. The bore area of the cylinder and the minimum wall thickness were known from the output force required from the hydraulic cylinder. From Khurmi and Gupta[33] the maximum wall thickness ( $t$ ) of the hydraulic cylinder was computed to be $0.0167 \mathrm{~m}$ from

$$
\begin{aligned}
& \mathrm{t}=\mathrm{r}_{\mathrm{i}}\left(\left(\delta_{\mathrm{t}} /\left(\delta_{\mathrm{t}}-2 \mathrm{p}\right)\right)^{1 / 2}-1\right) \\
& \text { Where } \\
& \mathrm{r}_{\mathrm{i}}=\text { Internal radius of cylinder }(\mathrm{m}), 50 \times 10^{-3} \mathrm{~m}, \\
& \mathrm{p}=\text { internal fluid pressure }\left(\mathrm{N} / \mathrm{m}^{2}\right), 3.82, \text { and } \\
& \delta_{\mathrm{t}}=\text { tangential stress }\left(\mathrm{N} / \mathrm{m}^{2}\right), 480 \times 10^{6} .
\end{aligned}
$$

Therefore, the minimum wall thickness is $0.017 \mathrm{~m}$ and it is considered adequate for the design.

The bolts and the uniform internal pressure distributed over the area support the thickness (T) of the end cover plate. This thickness is given by Khurmi Gupta[33] as

$\mathrm{T}=\mathrm{K} \mathrm{D}\left(\mathrm{P} / \delta_{\mathrm{t}}\right)^{1 / 2}$

Where

$\mathrm{D}=$ Diameter of end cover plate $(\mathrm{m}), 0.1$,

$\mathrm{K}=$ Coefficient depending upon the material of plate, 0.4 ,

$\mathrm{P}=$ Internal fluid pressure $\left(\mathrm{N} / \mathrm{m}^{2}\right), 38.2$, and

$\delta_{\mathrm{t}}=$ allowable design stress of cover plate material, $480 \mathrm{~N} / \mathrm{m}^{2}$.

The estimated plate thickness, accordingly, is $0.0118 \mathrm{~m}$.
The cylinder cover may be fastened by bolts or studs as shown in Figure 2. The following Eq. (3) was used in order to find the correct size and number of bolts [33]:

$\left(\pi \mathrm{D}_{\mathrm{i}}^{2} / 4\right) \mathrm{P}=\left(\pi \mathrm{d}_{\mathrm{c}}^{2} / 4\right) \delta_{\mathrm{tb}} \mathrm{n}$

Where

$\mathrm{P}=$ Internal fluid pressure $\left(\mathrm{N} / \mathrm{m}^{2}\right)$,

$\mathrm{D}_{\mathrm{i}}=$ internal diameter of cylinder $(\mathrm{m})$,

$\mathrm{d}_{\mathrm{c}}=$ core diameter of bolt $(\mathrm{m}), 16 \times 10^{-3} \mathrm{~m}$, and

$\delta_{\mathrm{tb}}=$ permissible tensile strength of the bolt.

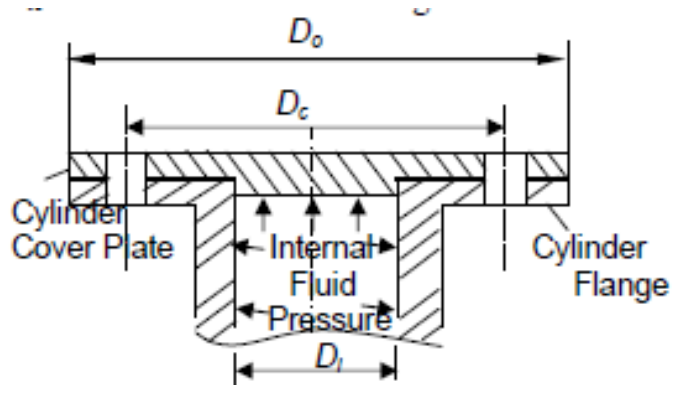

Figure 2: Arrangement for securing the cylinder cover plate with bolt.

The number of bolts can be found from the size of the bolt as known in Eq. (3). The number of bolts was computed to be 4 . The circumferential pitch, $\mathrm{D}_{\mathrm{p}}$ of the bolt of $0.0191 \mathrm{~m}$ determined the tightness of the joint between the cylinder and the end-cover plate as

$D_{p}=D_{i}+2 t+3 D_{c}$

Where

$\mathrm{t}=$ Thickness of cylinder wall $(\mathrm{m}), 17 \times 10^{-3} \mathrm{~m}$.

The minimum thickness (tf,) of the flange as determined from bending consideration aids in the design of cylinder flange. The two considered forces are fluid pressure and that used to separate the flange due to sealing resisted by the stress produced in the bolts. The force needed to separate the flange was computed to be $58.72 \mathrm{kN}$ as computed from

$$
\begin{aligned}
& \mathrm{F}=(\pi / 4) \mathrm{D}_{1}^{2} \mathrm{P} \\
& \text { Where } \\
& \mathrm{D}_{1}=\text { outside diameter of seal, } 134 \times 10^{-3} \mathrm{~m} .
\end{aligned}
$$

The flange bending about section A-A along which the flange is weakest, as in Figure 3, enables to calculate the thickness of the flange $\left(t_{f}\right)$. This bending is brought up due to the force in the two bolts and the fluid pressure inside the cylinder.

B

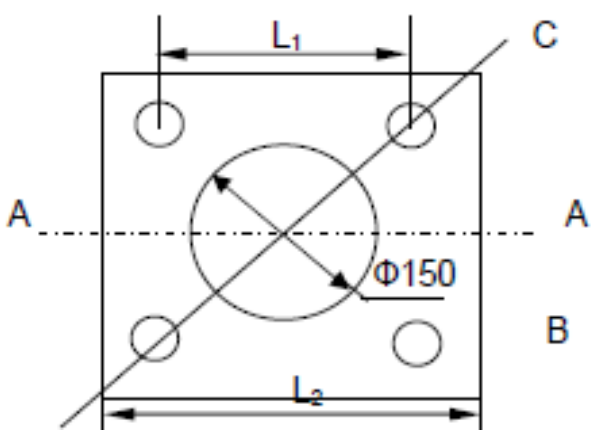

Figure 3: Square flange. 
A flange thickness of $0.0528 \mathrm{~m}$ is thus, estimated from

$\mathrm{T}_{\mathrm{f}}=(6 \mathrm{M}) /\left(\mathrm{b} \delta_{\mathrm{f}}\right)$

Where

$\mathrm{T}_{\mathrm{f}}=$ Flange thickness,

$\mathrm{b}=$ width of flange at section A-A, $22.2 \times 10^{-3} \mathrm{~m}$,

$\delta_{\mathrm{f}}=$ shear stress of flange material, $480 \mathrm{~N} / \mathrm{m}^{2}$, and

$\mathrm{M}=$ resultant bending moment, $5144.78 \mathrm{Nm}$.

The applied load was sustained by the required piston rod column size. The applied load is in alignment with the cylinder bore center line. The force applied to the rod column, the mounting situation of the cylinder and the stroke had effects on the applied load. Following Sullivan [32], the piston rod column size and the cylinder length under end thrust condition were computed. The size of the piston rod has a diameter of $0.09 \mathrm{~m}$ and is considered adequate for the design.

Internal and external leakages in the press under operating conditions of pressure and speed were prevented by seals. The selected static seal used the groove and ring principle. The groove dimension was calculated such that the $\mathrm{O}$ ring selected to be compressed from 15 to $30 \%$ in one direction and equal to $70-80 \%$ of the free cross-sectional diameter. The $\mathrm{O}$ ring can be compressed in one direction and expanded in the other. The groove dimension of $4 \times 3 \mathrm{~mm}$ was specified for the seal.

Mounting points that maintain proper relative positions of the units and parts mounted on it under all specified working conditions were provided by the frame. The general rigidity of the machine was provided from reference [34]. The design consideration is that of direct tension imposed on the pillars. Other frame members such as the platens (as in our case) are subjected to simple bending stresses.

The direct contact on the compressed object was evaluated by the upper and lower platens. The equal and opposite couple acting on the longitudinal plane led to a bending stress applied to the platens. The bending moment $(\mathrm{M})$ and shear force $(\mathrm{V})$ created in the beam were found to be $45 \mathrm{kN} / \mathrm{m}$ and $150 \mathrm{kN}$, respectively, as calculated from Beer and Johnston procedure [35].

The maximum bending moment $\mathrm{M}$ was utilized to compute modulus of section of the platens. The minimum depth (thickness), d, was computed to be $0.048 \mathrm{~m}$ from

$$
\begin{aligned}
& \mathrm{d}=((6 \mathrm{M}) /(\delta \mathrm{b}))^{1 / 2} \\
& \text { Where } \\
& \mathrm{M}=\text { Maximum bending moment, } 45 \mathrm{kN} / \mathrm{m}, \\
& \mathrm{b}=600 \times 10^{-3} \mathrm{~m}, \text { and } \\
& \delta=480 \times 106 \mathrm{~N} / \mathrm{m}^{2} .
\end{aligned}
$$

The maximum fluid discharge pressure from the pump was required to estimate the frictional loss in the system. It was about $47.16 \times 106 \mathrm{~N} / \mathrm{m}^{2}$. The lever of length of $0.8 \mathrm{~m}$ actuated the pumping action. The lever was calculated by assuming a maximum theoretical effort and taking the moment about the fulcrum.

\subsection{Hydraulic press specifications}

Specifications and dimensions of the present hydraulic press are listed in Table 1.

Table 1: Specifications and dimensions of the present hydraulic press.

\begin{tabular}{||c||c||c||}
\hline \hline No. & Type & Specification \\
\hline 1 & Maximum load & $150 \mathrm{KN}$ \\
\hline 2 & Internal fluid pressure & $3.82 \mathrm{~N} / \mathrm{m}^{2}$ \\
\hline 3 & Tangential stress & $480 \times 10^{6} \mathrm{~N} / \mathrm{m}^{2}$ \\
\hline 4 & Shear stress of flange & $480 \times 10^{6} \mathrm{~N} / \mathrm{m}^{2}$ \\
\hline 5 & Maximum bending moment & $45 \mathrm{KN} / \mathrm{m}$ \\
\hline 6 & Pumping pressure & $47.16 \times 10^{6} \mathrm{~N} / \mathrm{m} 2$ \\
\hline 7 & Piston stroke & $600 \mathrm{~mm}$ \\
\hline 8 & Piston diameter & $80 \mathrm{~mm}$ \\
\hline 9 & Thickness of cylinder wall & $17 \times 10^{-3} \mathrm{~m}$ \\
\hline 10 & Core diameter of bolt & $16 \times 10^{-3} \mathrm{~m}$ \\
\hline 11 & Internal radius of cylinder & $50 \times 10^{-3} \mathrm{~m}$ \\
\hline 12 & Length of the lever & $0.8 \mathrm{~m}$ \\
\hline 13 & Width of flange & $22.2 \times 10^{-3} \mathrm{~m}$ \\
\hline 14 & Thickness of cylinder wall & $17 \times 10^{-3} \mathrm{~m}$ \\
\hline 15 & O-ring seal dimension & $4 \mathrm{~mm} \times 3 \mathrm{~mm}$ \\
\hline 16 & Outside diameter of seal & $134 \times 10^{-3} \mathrm{~m}$ \\
\hline
\end{tabular}

The present hydraulic press is composed of three main parts: base, housing, circular plates, and press. These components are illustrated in Figure 4. The housing was supported on its base and the seeds were then fed into the housing. The housing has holes on all its sides to extract the oil from them. The oil was collected from the holes underneath the base. The oil yield from the hydraulic press was considerably lower than that from other methods. The yield of hydraulic press extraction was reduced to about $50 \%$ of total oil in the seeds because jatropha cakes absorb oil after removal of the applied force.
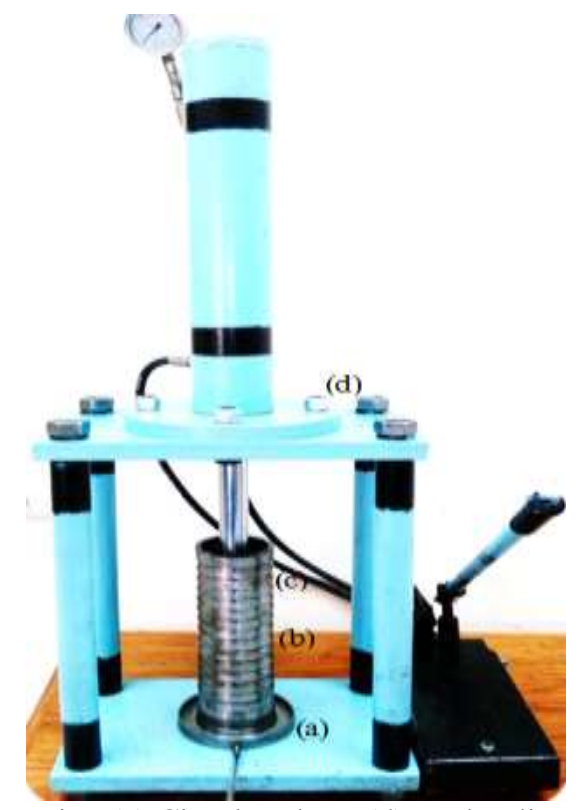

(a) L Housing (c) Circular plates (d) Hydraulic press Figure 4: Hydraulic press components. 


\subsection{Gas Chromatography (GC) measurement}

This is a technique used for measuring the fatty acid composition in oil sample which used mixture separation according to their boiling point. Oil was prepared by methylation process. In methylation process, Methanolic Sodium Hydroxide was prepared by dissolving $2 \mathrm{~g}$ of sodium hydroxide $(\mathrm{NaOH})$ in $100 \mathrm{ml}$ methanol. A clear solution was obtained by stirring the mixture for 2 minutes. Oil sample of $0.2 \mathrm{~g}$ was blended with $6 \mathrm{ml}$ of Methanolic sodium hydroxide solution. Then the mixture was refluxed for 10 minutes. Then, $10 \mathrm{ml}$ of a mixture solution, consisted of $30 \mathrm{ml}$ concentrated Hydrochloric acid $(\mathrm{HCl})$ and 20 $\mathrm{ml}$ methanol, was added and refluxed for another 10 minutes. Then, $10 \mathrm{ml}$ of hexane was mixed and refluxed for 2 minutes and allowed to cool. Finally, a distilled water of $0 \mathrm{ml}$ was added, and the mixture was left to separate. The upper layer was collected and dried by calcium chloride. This sample is ready for GC analysis, [36,37].

The gas chromatography unit of Hewlett Packard model 5890 consists of a flame ionization detector, an oven and a fused silica capillary column was used for GC analysis. A small syringe is used to inject the oil. The injector is contained in an oven whose temperature is enough to boil the sample. The sample is carried into the column by a helium carrier gas and its temperature was varied from 50 to $250 \mathrm{C}[37,38]$.The retention indices of the fatty acids methyl esters are calculated using fatty acids methyl esters standards (C4-C22) from Sigma Aldrich Company standards. The triglyceride as saturated ( $\mathrm{Cn}: 0)$, monounsaturated $(\mathrm{Cn}: 1)$ and polyunsaturated with two or three double bonds ( $\mathrm{Cn}: 2,3)$ were contained in the Fatty acid. Vegetable oils are potential feedstock's for biodiesel production, but the fuel quality can be affected by the oil composition.

\section{Results and Discussion}

\subsection{Free Fatty Acid (FFA) percentage}

The extraction method changes the oil color and hence its quality. The extraction temperature influences physical and chemical properties of the oil. The extracted oil oxidation is according to the applied extraction temperature. Higher extraction temperature for long time results in darker color extracted oil. Extraction temperature effects on oil color and FFA $\%$, and this is affected on the biodiesel production process.

FFA percentage in the oil was estimated by titration. In this process, 4 grams of sodium hydroxide $(\mathrm{NaOH})$ were dissolved in one liter of distilled water to get $(0.1 \mathrm{NaOH})$ solution. The end point was determined by Phenolphthalein indicator. One $\mathrm{ml}$ of jatropha oil was dissolved in $10 \mathrm{ml}$ of isopropyl alcohol. The mixture was then warmed and stirred until all the oil dissolved in the alcohol and the mixture turns clear. Two drops of phenolphthalein were added. $\mathrm{NaOH}$ solution is added drop by drop to the mixture, with stirring all the time until the solution stays pink for 10 seconds. FFA percentage calculation from titration method was estimated from Refs. [39,40]. For hydraulic extraction, $6.5 \mathrm{ml}$ of $0.1 \mathrm{NaOH}$ solutions was estimated to produce $5 \%$ FFA

$$
\text { FFA } \%=\left(28.2 \mathrm{~V}_{\text {titr }} \mathrm{n}\right) / \mathrm{w}
$$

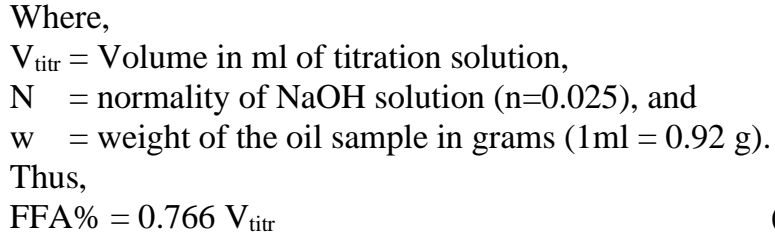

\subsection{Gas Chromatography analysis}

Vegetable oil should have lower saturation and Poly unsaturation. Jatropha oil contains linoleic, oleic, palmitic and stearic fatty acids. Oil extraction by hydraulic press is a standard process because the seeds were pressed without heat as given in Table 3. Extraction temperature affects oleic acid content which is high for hydraulic extraction. Jatropha oil can be classified as oleic-linoleic oil. Jatropha seeds have higher oleic fatty acid than other vegetable oils as shown in Table 3 and Figure 5. Rich polyunsaturated acids in the oil such as linoleic and linolenic acids gave poor oxidation stability biodiesel. Higher degree of unsaturation led to have higher freezing point, poor flow characteristic at lower temperatures and need preheating before combustion. Jatropha oil of mono unsaturation is higher than other vegetable oils, so this oil is a good candidate for biodiesel production. Oil oxidation depends on the fatty acid composition. Jatropha oil with higher content of unsaturated fatty acid has a relatively short induction period. Peak values in Figure 5 show areas which give relation between time and relative abundance as shown in Table 3.

Table 3: Fatty acid composition of jatropha oil.

\begin{tabular}{|c||c|c|}
\hline No. & Fatty acid & Hydraulic extraction \\
\hline \hline 1 & Palmitic (16:0) & 17.69 \\
\hline 2 & Stearic $(18: 0)$ & 3.16 \\
\hline 3 & Oleic $(18: 1)$ & 22.64 \\
\hline 4 & Linoleic $(18: 2)$ & 51.63 \\
\hline
\end{tabular}

Jatropha biodiesel is unstable and easily oxidized in air. GC was tested in GC unit at Central Lab., National Research Centre.

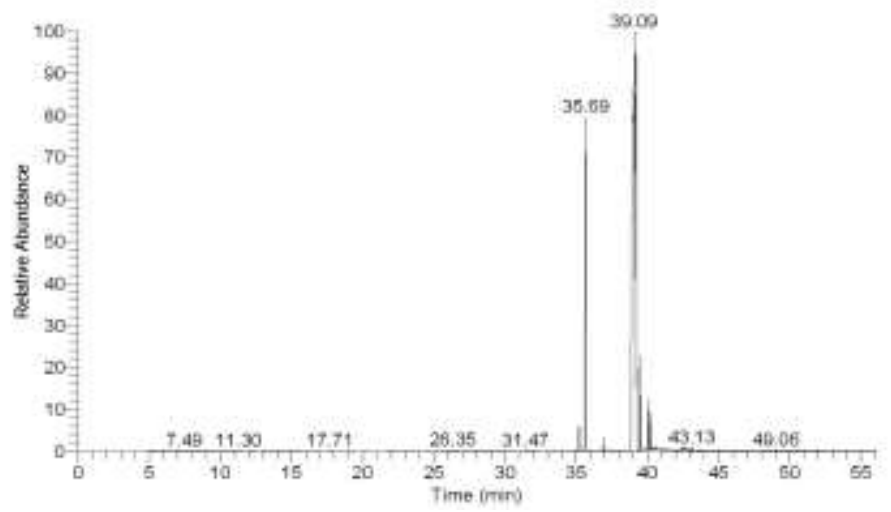

Figure 5: GC for oil extraction by hydraulic press.

\subsection{Influence of extraction time on oil yield}

Extraction process time is a vital parameter in determining the best extraction method. Extracted oil from the seeds under pressure had more than $4 \mathrm{hrs}$. A sample of one $\mathrm{kg}$ jatropha seeds was used for calculating the consumed time. It takes more than 
$12 \mathrm{hrs}$ for pressing $1 \mathrm{~kg}$ of Jatropha seeds. The extraction time is 750 minutes for oil extraction. The maximum extraction yield is $11 \%$ for. The percentage of oil content in jatropha seeds can be calculated from Refs. [41,42].

Percentage of oil yield $=[($ Weight of oil obtained $) /($ Weight of seeds)] x 100

\subsection{Effect of Temperature on oil density}

The variations in densities at different temperatures of extracted jatropha oil are shown in Figure 6. The results indicate that oil extraction temperature has a significant effect on the density. The measured value of oil density by the test method (ASTM D-1298) of jatropha oil at a temperature of $20 \mathrm{C}$ is 916 $\mathrm{kg} / \mathrm{m}^{3}$ for hydraulic as compared to only $829 \mathrm{~kg} / \mathrm{m}^{3}$ for diesel oil. The density of the oil decreased with the increase in temperature. The density is inversely proportional to the oil temperature. The density can be correlated as a linear relationship $(\rho=-0.5247 \mathrm{~T}+$ 923.79) with oil temperature. Jatropha oil density variation at different temperatures was referenced to diesel oil $\left(825 \mathrm{~kg} / \mathrm{m}^{3}\right)$.

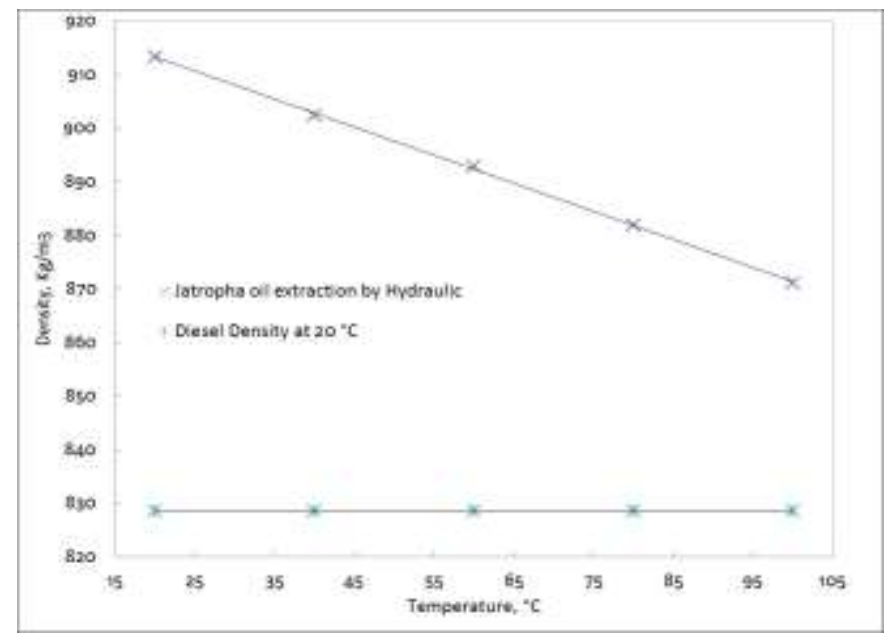

Figure 6: Effect of temperature on oil density.

\subsection{Effect of Temperature on oil viscosity}

Viscosity of jatropha oil is much higher than hydrocarbon diesel oil. The measured value of dynamic viscosity by test method ASTM D-445 for Jatropha oil at $40{ }^{\circ} \mathrm{C}$ is $7.5 \mathrm{Cp}$ for as compared to only $1.188 \mathrm{Cp}$ for diesel oil at the same temperature. Jatropha oil viscosity variation at different temperatures was referenced to diesel oil $(1.188 \mathrm{Cp})$. However, the viscosity decreases with increase in oil temperature. This can be inferred by comparing the values of oil viscosities at 40,60, 80,60 and $100 \mathrm{C}$ for Jatropha oil. Preheating of bio oil fuel lines is one of the solutions to overcome the problems related to the higher oil viscosity in diesel engines. The viscosity can be correlated and fitted for the extraction processes. The viscosity decreases as a power function according to the increase in oil temperature $(. \mu=$ $\left.84.624 \mathrm{~T}^{-0.809}\right)$. Correlation of viscosity at different temperatures is helpful in predicting and calculating viscosity of extracted oil from Egyptian Jatropha seeds. The variations in viscosity at different temperatures of jatropha oil are indicated in Figure 7.

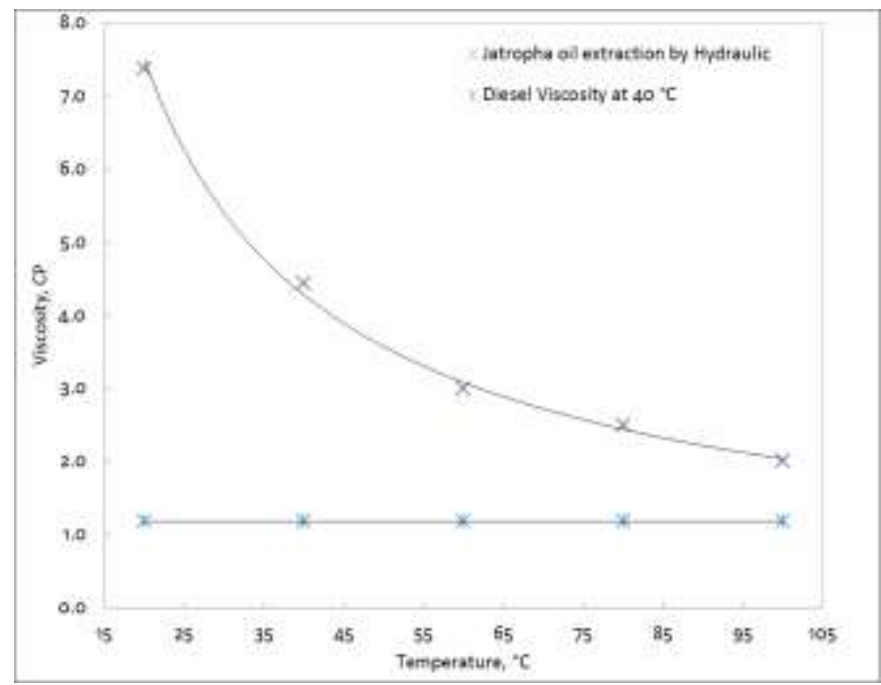

Figure 7: Effect of temperature on oil viscosity.

\subsection{Effect of hydraulic extraction on jatropha oil properties}

Calorific value of jatropha oil extracted by the hydraulic process was $39201 \mathrm{~kJ} / \mathrm{kg}$, as stated in Table 7 . The fuel calorific value is defined as the available heat to produce the required engine output power. Therefore, the calorific value is important in the choice of an alternative fuel for a diesel engine for higher engine performance. Measured cetane number for jatropha oil extracted by the hydraulic process is 39 . Cetane number is a measure of fuel combustion quality in diesel engines. Cetane number and ignition delay affect engine performance, cold starting, and warm up. The higher Cetane number led to shorter ignition delay and engine performance reduction. The flash point of jatropha oil extracted hydraulically is $146{ }^{\circ} \mathrm{C}$. Flash point is critical for storage and safety handling of the oil. Flash points of jatropha oil is higher than crude diesel, so, jatropha oil is relatively less hazardous, safe in handling and storage with respect to diesel fuel as recorded in Table 7.

Table 7: Chemical and physical properties of Jatropha oil compered to pure diesel.

\begin{tabular}{|c||c||c||c||c||}
\hline No. & Oil properties & Test method & $\begin{array}{c}\text { Jatropha oil } \\
\text { extracted }\end{array}$ & $\begin{array}{c}\text { Diesel } \\
\text { oil }\end{array}$ \\
\hline \hline 1 & Flash point, ${ }^{\circ} \mathrm{C}$ & ASTM D-92 & 146 & 75 \\
\hline 2 & Cetane number & ASTM D-13 & 39 & 45 \\
\hline 3 & $\begin{array}{c}\text { Calorific } \\
\text { value, } \mathrm{kJ} / \mathrm{kg}\end{array}$ & $\begin{array}{c}\text { ASTM } \\
\text { D-240 }\end{array}$ & 39201 & 42000 \\
\hline
\end{tabular}




\section{Conclusions}

The main goal of this research is to design, manufacture, and test a hydraulic press to produce higher yield and optimum physical and chemical properties of oil extracted from Egyptian jatropha seeds. The present results led to these conclusions:

1. Time of oil extraction process from jatropha seeds is 720 minutes at a yield of $11 \%$.

2. Higher extraction temperature caused darker color of the oil because of oxidation. Jatropha oil extracted by hydraulic pressing gave lighter oil color because of the lower FFA of $5 \%$ for the produced oil. This method is characterized for higher oil production .

3. The density and viscosity of the extracted oil decreased with temperature increase. The deduced correlations of viscosity and density in relation with temperatures can be correctly used in predicting the viscosity and density for the extracted oil from Egyptian Jatropha seeds.

4. Flash point of jatropha oil extracted by hydraulic press is higher than fossil diesel oil, so, handling and storage of the oil is relatively less hazardous as compared to diesel fuel. The calorific value of jatropha oil extracted by the hydraulic process was $39201 \mathrm{~kJ} / \mathrm{kg}$.

5. Jatropha oil contains oleic, linoleic, palmitic and stearic fatty acids. Jatropha biodiesel oxidation instability increased for hydraulic extraction due to its content of oleic and linoleic acids.

\section{Conflict of Interest}

The authors declare no conflict of interest.

\section{Acknowledgment}

The authors would like to acknowledge the support of the National Research Center, Egypt, and the Mechanical Engineering Department, Al-Azhar University, Egypt.

\section{References}

[1] S. Raja, Biodiesel production from jatropha oil and its characterization, Res J Chem Sci, 2011.

[2] S.M.A.S.M.A. Ibrahim, K.A.A. Abed, M.S.S. Gad and H.M.M. Abu Hashish, Optimum oil yield from Egyptian Jatropha seeds using screw press, Int. J. Mech. Mechatronics Eng. 17, pp. 47-56, 2017.

[3] M.Y. Koh, T.I. Mohd. Ghazi and T.I.M. Ghazi, A review of biodiesel production from Jatropha curcas L. oil, Renew. Sustain. Energy Rev. 15, pp. 2240-2251, 2011.

[4] R.L. Evangelista, T.A. Isbell and S.C. Cermak, Extraction of pennycress (Thlaspi arvense L.) seed oil by full pressing, Ind. Crops Prod. 37, pp. 76-81, 2012.

[5] A. Oyinlola, A. Ojo and L.O. Adekoya, Development of a laboratory model screw press for peanut oil expression, J. Food Eng. 64, pp. 221-227, 2004.
[6] R.C. Pradhan, S. Mishra, S.N. Naik, N. Bhatnagar and V.K. Vijay, Oil expression from Jatropha seeds using a screw press expeller, Biosyst. Eng. 109, pp. 158-166, 2011.

[7] M. Costa and D. Piazzullo, Biofuel Powering of Internal Combustion Engines: Production Routes, Effect on Performance and CFD Modeling of Combustion, Front. Mech. Eng. 4, 2018.

[8] M.D. Luque de Castro and L.E. García-Ayuso, Soxhlet extraction of solid materials: An outdated technique with a promising innovative future, Anal. Chim. Acta 369, pp. 1$10,1998$.

[9] S.M.A.S.M.A. Ibrahim, K.A.A. Abed, M.S.S. Gad and H.M.M. Abu Hashish, Comparison of different methods for producing bio oil from Egyptian jatropha seeds, Biofuels, pp. 1-12, 2017.

[10] J. Sriti, T. Talou, M. Faye, G. Vilarem and B. Marzouk, Oil extraction from coriander fruits by extrusion and comparison with solvent extraction processes, Ind. Crops Prod. 33, pp. 659-664, 2011.

[11] M. Naeem, H.M. Abu Hashish and H. Zahran, Optimize the Roselle (Hibiscus Sabdariffa L.) Seeds Oil Extraction Using Screw Press, 32, 2017.

[12] M.S.M. Gad, H. Mustafa and H.M.M. Abu Hashish, Effect of Egyptian Roselle biodiesel on performance and emissions of diesel engine, Egypt. J. Chem. 61, pp. 700-710, 2018.

[13]C. Ofori-Boateng, L. Keat Teong and L. Jitkang, Comparative exergy analyses of Jatropha curcas oil extraction methods: Solvent and mechanical extraction processes, Energy Convers. Manag. 55, pp. 164-171, 2012.

[14]F.K.F.K. El-Baz, M.S.S. Gad, S.M.S.M. Abdo and H.M.M. Abu Hashish, Comparative study of performance and exhaust emissions of a diesel engine fueled with algal, used cooked and Jatropha oils biodiesel mixtures, Int. J. Mech. Mechatronics Eng. 17, pp. 90-100, 2017.

[15] Comparison of oil press for jatropha oil - A review. Czech Academy of Agricultural Sciences, 2015.

[16] S.M.M. Habib, M.M.A. El-Sharabasy, M.M. Badr and M.M. El-Kholy, Construction and Performance Evaluation of a Screw Press Machine to Extract Jatropha Oil, 46 , 2019.

[17]A. Abd El-Kader and H. Abu Hashish, Encapsulation techniques of food bioproduct, Egypt. J. Chem., 2019.

[18] H.M. Abu Hashish and A.E. Abd El-Kader, Soybean oil and soy flakes production simultaneous using newly screw press design, , Biosci. Res. 16, pp. 17-25, 2019.

[19] D.A. Kamel, H.A. Farag, N.K. Amin, A.A. Zatout and R.M. Ali, Smart utilization of jatropha (Jatropha curcas Linnaeus) seeds for biodiesel production: Optimization and mechanism, Ind. Crops Prod. 111, pp. 407-413, 2018.

[20]A. Chapuis, J. Blin, P. Carré and D. Lecomte, Separation efficiency and energy consumption of oil 
expression using a screw-press: The case of Jatropha curcas L. seeds, Ind. Crops Prod. 52, pp. 752-761, 2014.

[21]P. Evon, I. Amalia Kartika, M. Cerny and L. Rigal, Extraction of oil from jatropha seeds using a twinscrew extruder: Feasibility study, Ind. Crops Prod. 47, pp. 33-42, 2013.

[22]E. Subroto, R. Manurung, H.J. Heeres and A.A. Broekhuis, Mechanical extraction of oil from Jatropha curcas L. kernel: Effect of processing parameters, Ind. Crops Prod. 63, pp. 303-310, 2015.

[23] M.Y. Abduh, C.B. Rasrendra, E. Subroto, R. Manurung and H.J. Heeres, Experimental and modelling studies on the solvent assisted hydraulic pressing of dehulled rubber seeds, Ind. Crops Prod. 92, pp. 67-76, 2016.

[24]D. Herak, A. Kabutey and P. Hrabe, Oil point determination of Jatropha curcas L. bulk seeds under compression loading, Biosyst. Eng. 116, 2013.

[25] J. Rodrigues, I. Miranda, J. Gominho, M. Vasconcelos, G. Barradas, H. Pereira et al., Modeling and optimization of laboratory-scale conditioning of Jatropha curcas L. seeds for oil expression, Ind. Crops Prod. 83, pp. 614-619, 2016.

[26]P. Shivani, P. Khushbu, N. Faldu, V. Thakkar and R.B. Shubramanian, Extraction and analysis of Jatropha curcas L. seed oil, African J. Biotechnol. 10, pp. 18210-18213, 2011.

[27] M. Sumaila, A. Okonigbon and A. Ibhadode, Design and Manufacture of a 30-ton Hydraulic Press, 14, pp. 196-200, 2011.

[28] B.W. Niebel, A.B. Draper and R.A. Wysk, Modern Manufacturing Process Engineering, McGraw-Hill, 1989.

[29] E.P. (Ernest P. DeGarmo, J.T. Black and R.A. Kohser, Materials and Processes in Manufacturing, Wiley, 1999.

[30] P.C. Sharma, A Textbook of Production Engineering, S. Chand \& Co, 1999.

[31] K. Lange, Handbook of Metal Forming, Society of Manufacturing Engineers, 1995.

[32] J.A. Sullivan, Fluid Power: Theory and Applications, Prentice Hall, 1989.

[33] R.S. Khurmi and J.K. Gupta, A Textbook of Machine Design (S.I. Units) : [A Textbook for the Students of B.E. / B. Tech., U.P.S.C. (Engg. Services); Section "B" of A.M.I.E. (1)], Eurasia Publishing House, 2005.

[34] N. Ignatyev, N. Acherkan, Y. Mikheyev and N. Weinstein, Machine Tool Design, Machine Tool DesignUniversity Press of the Pacific, 2000.
[35] F.P. (Ferdinand P. Beer, E.R. (Elwood R. Johnston, J.T. DeWolf and D.F. (David F. Mazurek, Mechanics of Materials, .

[36] A.H.H. Tambunan, J.P.P. Situmorang, J.J.J. Silip, A. Joelianingsih and T. Araki, Yield and physicochemical properties of mechanically extracted crude Jatropha curcas Loil, Biomass and Bioenergy 43, pp. 12-17, 2012.

[37]E. Ankapong, The Influence of Physicochemical Characteristics of Vegetable Oils on the Quality of Biodiesel Produced from Palm Oil, Palm Kernel Oil, Refined, Dessertation, Kwame Nkrumah Univ. Sci. 2010

[38] S. Bojan and S. Durairaj, Producing biodiesel from high free fatty acid Jatropha curcas oil by a two step methodan Indian case study, J. Sustain. Energy Environ, 2012 .

[39]A. Tiwari, A. Kumar and H. Raheman, Biodiesel production from jatropha oil (Jatropha curcas) with high free fatty acids: an optimized process, Biomass and bioenergy, 2007 .

[40] G. Kombe, A. Temu and H. Rajabu, High free fatty acid (FFA) feedstock pre-treatment method for biodiesel production, Proc. 2nd Int. Conf. Adv., 2012.

[41]F.K. Forson, E.K. Oduro and E. Hammond-Donkoh, Performance of jatropha oil blends in a diesel engine, Renew. energy 29, pp. 1135-1145, 2004.

[42] M.S. Shehata, Emissions, performance and cylinder pressure of diesel engine fuelled by biodiesel fuel, Fuel 112, pp. 513-522, 2013. 